\title{
The evolution of trauma care in the Netherlands over 20 years
}

\author{
Falco Hietbrink ${ }^{1}$ (D) Roderick M. Houwert ${ }^{1} \cdot$ Karlijn J. P. van Wessem $^{1} \cdot$ Rogier K. J. Simmermacher ${ }^{1}$. \\ Geertje A. M. Govaert ${ }^{1}$. Mirjam B. de Jong ${ }^{1}$. Ivar G. J. de Bruin ${ }^{1}$. Johan de Graaf ${ }^{1}$. Loek P. H. Leenen ${ }^{1}$
}

Received: 30 September 2019 / Accepted: 15 November 2019 / Published online: 23 November 2019

(c) The Author(s) 2019

\begin{abstract}
Introduction In 1999 an inclusive trauma system was initiated in the Netherlands and a nationwide trauma registry, including all admitted trauma patients to every hospital, was started. The Dutch trauma system is run by trauma surgeons who treat both the truncal (visceral) and extremity injuries (fractures).

Materials and Methods In this comprehensive review based on previous published studies, data over the past 20 years from the central region of the Netherlands (Utrecht) was evaluated.

Results It is demonstrated that the initiation of the trauma systems and the governance by the trauma surgeons led to a regionwide mortality reduction of 50\% and a mortality reduction for the most severely injured of $75 \%$ in the level 1 trauma centre. Furthermore, major improvements were found in terms of efficiency, demonstrating the quality of the current system and its constructs such as the type of surgeon. Due to the major reduction in mortality over the past few years, the emphasis of trauma care evaluation shifts towards functional outcome of severely injured patients. For the upcoming years, centralisation of severely injured patients should also aim at the balance between skills in primary resuscitation and surgical stabilization versus longitudinal surgical involvement.

Conclusion Further centralisation to a limited number of level 1 trauma centres in the Netherlands is necessary to consolidate experience and knowledge for the trauma surgeon. The future trauma surgeon, as specialist for injured patients, should be able to provide the vast majority of trauma care in this system. For the remaining part, intramural, regional and national collaboration is essential
\end{abstract}

Keywords Trauma systems $\cdot$ Mortality $\cdot$ Outcome analysis $\cdot$ Centralisation

\section{Introduction}

Assessment, resuscitation and treatment of injured patients have seen major changes over the past 20 years in the Netherlands. The improvements that derived from these developments, in terms of decreased in-hospital mortality and morbidity, are mainly attributed to two factors. First of all, changes in the organizational structure of the trauma system were made. Second, trauma is nowadays more handled as an unique disease entity. The current system is, as in most countries, build on the holistic character of the trauma surgeon as a specialist for these patients. The data in this review paper are extracted from previous publications involving the

Falco Hietbrink

F.Hietbrink@umcutrecht.nl

1 Department of Surgery, University Medical Centre Utrecht, Heidelberglaan 100, 3584 CX Utrecht, The Netherlands trauma network "Midden Nederland", which comprises the central region of the Netherlands and is made possible due to continuous prospective data gathering and outcome analysis.

\section{The Dutch system}

All over the world, the (trauma) surgeon treats (severely) injured patients. In many countries, such as the USA and the Scandinavian countries, the emphasis is put on the most lethal truncal injuries. In these countries, the visceral surgeon is in charge of trauma care. In other countries, such as the German-speaking countries, a more quantitative approach is taken and the orthopaedic surgeon is nowadays in charge of trauma care, as over $80 \%$ of the surgical procedures in injured patients concerns extremity (fracture) surgery[1]. 
In the Netherlands, the trauma surgeon is a general surgeon with trauma-orthopaedic competences. The differentiation from general all-round surgeon towards trauma surgery started in the eighties and came to its current form in the early nineties. Nowadays, the Dutch trauma surgeon follows 4 years of training in general surgery and thereafter trains another 2 more years mainly in trauma surgery. In these last 2 years, additional training and courses in resuscitation, visceral and fracture surgery are required (ATLS refresher, DSTC, AO advanced). Additional fellowships are available to acquire specific competences when needed. Thereafter, trauma surgeons update their skills by a variety of courses and additional training in the wet-lab or cadaver training.

As a result, in the Netherlands the trauma surgeon treats both visceral injuries (neck/chest/abdomen/pelvis) and extremity injuries (including soft tissue injuries and fracture treatment) [2, 3]. In addition, the trauma surgeon in the Netherlands has knowledge of physiological disturbances and cares for the resuscitation of the patient in the acute phase $[4,5]$. Thereafter, the surgeon is actively involved in the intensive care in our level 1 centre. This requires a broad spectrum of skills, based on solid education and a reliable training process.

This skill set enables the Dutch trauma surgeon to be involved with their patients in a longitudinal aspect during resuscitation and treatment $[6,7]$. This process starts in the emergency department (ED) as the trauma surgeon in our level 1 trauma centre attends every trauma team activation (following high-energy mechanism supplemented with, but not solely depending on, vital parameters or stability). Thereafter, treatment continues through the operating room (OR) or intensive care (ICU), to the trauma ward and finally to the rehabilitation clinic if necessary. In the period after discharge, the trauma surgeon is also the primary person of contact in the out-patient clinics. There are, however, some local differences in the involvement of the trauma surgeons. For instance, in our hospital spine surgery is performed by a combination team of orthopaedic and neurosurgeons. Furthermore, prosthesis is placed by orthopaedic surgeons only, in contrast to other Dutch hospitals where other choices are made. Nevertheless, the generalistic background and holistic view of the Dutch trauma surgeon and specific dedication to trauma optimizes the integral treatment of injured patients. Furthermore, with the combination of both truncal and extremity trauma, there is sufficient volume to employ fulltime trauma surgeons without the need for a second specialty in a more elective or non-trauma setting [8]. In recent years, however, this generalistic character is challenged in an environment of public opinion and far-reaching legislation that demands ongoing sub-specialisation of physicians.

\section{The evolution of mortality in trauma}

In 1999 the Netherlands implemented an inclusive trauma system, which organized the country in 11 trauma regions [9]. The goal of this inclusive system is to present all patients on a timely basis at the right hospital, with the centralisation of the most severely injured patients in level 1 centres [1023]. The less severely injured patients are ideally treated at level 2 and level 3 centres. The composition of our region is described in Table 1, including a short description of the designated trauma level.

This organizational change had a major impact on trauma care, as it did in most countries that implemented inclusive trauma systems $[24,25]$. The data presented in every time period is based on previous publications and where possible adjusted odd ratios presented in those publications were used [10-23]. Before centralisation (step 1) a regional mortality rate of $2.6 \%$ was documented, of which $40 \%$ died due to exsanguination. Before 1999 the exsanguination percentage in the academic teaching hospital (the University Medical Centre Utrecht, later to be the level 1 trauma centre) was $17 \%$. After centralisation (period 2003-2005) a concentration of severely injured (multitrauma) patients was noted (multitrauma defined as ISS $>15$ ). This increase in trauma severity was accompanied by an increase in crude mortality (Table 2). However, when corrected for age and injury severity [based on the Injury Severity Score (ISS)], a reduction in odds ratio was found for mortality. This reduction in mortality could be attributed to a decrease in death due to exsanguination and organ failure. In the years thereafter, a further maturation of the trauma system took place (step 2).

Parallel to the logistical optimization, there was a change in the surgical approach of severely injured patients. In conjunction to damage control surgery, the damage control

Table 1 General description of trauma centre level layout in the Netherlands

\begin{tabular}{|c|c|c|}
\hline Trauma center & Function & $\begin{array}{l}\text { Number in } \\
\text { our region }\end{array}$ \\
\hline Level 1 & $\begin{array}{l}\text { For the most severely injured patients, multitrauma patients and patients with brain injury. Fully equipped } \\
\text { trauma center with twenty-for-seven open ER, helicopter landing pad, neurosurgical availability, immediate } \\
\text { CT-scanning and angio-suit available and OR available }<15 \mathrm{~min}\end{array}$ & 1 \\
\hline Level 2 & For patients with isolated or multiple injuries. Not for multitrauma patients or patients with brain injuries & 3 \\
\hline Level 3 & For patients with isolated injuries & 2 \\
\hline
\end{tabular}


Table 2 Number of patients and mortality per time period

\begin{tabular}{|c|c|c|c|c|}
\hline Time period & $1996-1998$ & $2003-2005$ & $2006-2009$ & 2014-2016 \\
\hline Hallmark & Before centralization & After centralization & Optimizing trauma & Mind-set trauma \\
\hline Injury Severity Score (ISS) in level 1 trauma centre (mean) & 9.6 & 12.4 & 13.8 & 12.4 \\
\hline $\begin{array}{l}\text { Number of total admitted injured patients in level } 1 \text { trauma } \\
\text { centre ( } n \text { /year; mean) }\end{array}$ & 1401 & 1193 & 863 & 1348 \\
\hline Multitrauma patients in level 1 trauma centre $(n / \text { year; mean })^{\mathrm{a}}$ & 156 & 186 & 225 & 358 \\
\hline Mortality in trauma region ${ }^{\mathrm{b}}$ & $2.6 \%$ & $2.3 \%$ & NA & $1.2 \%$ \\
\hline $\begin{array}{l}\text { Odds ratio (OR) regional to previous period (corrected for } \\
\text { age and ISS) }\end{array}$ & Reference & 0.84 & NA & NA \\
\hline Mortality in level 1 trauma centre ${ }^{\mathrm{b}}$ & $7.9 \%$ & $8.5 \%$ & $8.2 \%$ & $5.2 \%$ \\
\hline $\begin{array}{l}\text { Odds ratio (OR) level } 1 \text { trauma centre to previous period } \\
\text { (corrected for age and ISS) }\end{array}$ & Reference & 0.61 & 0.74 & 0.54 \\
\hline \multicolumn{5}{|l|}{ Cause of mortality in level 1 centre } \\
\hline Exsanguination & $17 \%$ & $9 \%$ & $8 \%$ & $3 \%$ \\
\hline Organ failure & $25 \%$ & $18 \%$ & $5 \%$ & $2 \%$ \\
\hline Neurological injuries & $40 \%$ & $57 \%$ & $68 \%$ & $85 \%$ \\
\hline
\end{tabular}

Data in this table were extracted from the previously published articles. The cited articles were based on the prospective database from the trauma region

$N A$ not available

${ }^{a}$ Multitrauma was defined as an injury severity score (ISS) $>15$

${ }^{\mathrm{b}}$ The regional mortality rate is based on all trauma-related admissions. Similar, the mortality rate of the level 1 center is based on all patients admitted through the emergency department of that hospital

principles are more frequently applied not only for the visceral surgery part but also in the resuscitation process (damage control resuscitation) and in the treatment of fracturerelated injuries (damage control orthopaedics) [26-28]. Furthermore, non-operative management approaches are more widely acknowledged and appreciated. Moulded by education, training and positive results after the implemented modifications the mind-set of the trauma surgeon changed (step 3). The acute surgical patient and the trauma patient in particular is more and more being treated differently in comparison to the patient seen in the elective process. Trauma is regarded as a different entity, an unique disease. Decisionmaking, indication, timing and technique are all tailored to these patients. In the latest period (2014-2016), a gradual increase in the number of multitrauma patients was observed to over 350 annually, with an average ISS of 25 and a crude mortality of $14 \%$. The calculated result is a further reduction in mortality compared to the previous period of almost $50 \%$. This can not only be attributed to improved care immediately at presentation. Also for instance, by means of the $24 \times 7$ in house presence of a trauma surgeon it is attempted to further reduce the 'failure-to-rescue' rate in our centre [19]. These combined measures resulted that to date, the most important cause of death is neurotrauma $(>80 \%)$. Even more, in most cases of extensive neurotrauma it is a medical decision to stop treatment after adequate resuscitation and when a complete overview of the patients history and comorbidities is retrieved $[16,17]$. Finally, next to the improved mortality rates, the care for trauma patients becomes increasingly efficient. Currently, the average length of stay in the hospital is 7 days, compared to 14 days before centralization. The length of stay at the ICU demonstrated a similar pattern with a reduction of 8-5 days in the same period.

This process is not confined to the level 1 trauma centre, but our whole trauma region (Utrecht) is part of this development. On the one hand, there is concentration of multitrauma patients and complex monotrauma patients (i.e. after high-energy mechanism, open fractures, patients with multiple comorbidities) in the level 1 centre. These patients require a multidisciplinary approach and benefit from physicians with experience in this pathology. On the other hand, there is concentration of patients with a single injury in the regional hospitals, who developed specific-efficient-patient pathways for these patient populations. This lateralisation (step 4) led to a reduction in mortality and more efficient care in for instance the geriatric patient with a hip fracture [22].

In conclusion, over the past 20 years the incremental steps and changes resulted in a regional reduction of $50 \%$ in crude mortality and a reduction in mortality adjusted for age and ISS of $75 \%$ in our level 1 trauma centre. 


\section{A shift in outcome measurements: from mortality to functionality}

To date, our level 1 trauma centre has a 5\% mortality rate for trauma patients, with neurotrauma accounting for most of the fatalities. Due to the major reduction in mortality over the past few years, the opportunity arises to shift focus to the functional outcome of these patients. This is a significant change in perspective. However, especially in the multitrauma patient, this outcome can be difficult to determine. In consequence of the nature of the injuries, multitrauma patients are frequently excluded from functional outcome studies in a general trauma population, as these often severely injured patients have a "negative" impact on the study results. Negative results could be undesirable, as functional outcome studies are not only used to measure patient-reported outcomes, but also more and more to judge the quality of the care. As a result, little is known about the functional recovery and patient-reported outcomes of multitrauma patients. Recent results, however, have demonstrated that multitrauma patients can have a satisfying functional outcome and quality of life as well [18]. Furthermore, șover $90 \%$ of the patients who survived their neurotrauma eventually went home or to a rehabilitation centre. Of this latter group $>70 \%$ recovers to an acceptable level [17]. This also holds true for instance for patients with specific injuries like rib fractures, hand- or wrist injuries or complex foot injuries [29-31].

\section{Further centralisation of trauma care?}

In the Netherlands, over 4000 multitrauma patients a year are admitted to any hospital. Current legislation demands that $>90 \%$ of the multitrauma patients are presented to and treated in a level 1 trauma centre. However, with this rate in 2017 being $53-78 \%$ in the different trauma regions of the Netherlands, this criterion has not yet been met [32]. One of the factors that hampers this triage rate is that the ISS is a post-assessment score. With the current questionable definition of the most severely injured patients (multitrauma or ISS $>16$ ) and the lack of field triage criteria to adequately predict this definition, to us this goal of $90 \%$ seems unreachable [32]. The discussion what the ideal definition of multitrauma should be is ongoing, but currently the ISS $>16$ is the one still used in the Netherlands. Furthermore, new tools are to be developed to improve field triage, but secondary transfers will remain needed to get all the patients in the correct level of care, both to and from level 1 [33]. To stimulate this process, government, health insurance companies and hospital boards should make active policy on this subject [34].
The optimal number of multitrauma patients per level 1 centre is much debated, but a plateau phase is suggested in the level of competence, knowledge and skills of the trauma team at approximately 600 of these patients per year [35, $36]$. With this amount of severely injured patients logistical optimization and hospital efficacy also peaks. Nevertheless, bigger is not always better. In the largest centres of the world, with over $>2000$ severely injured patients per year, the primary resuscitation and surgical stabilization are generally organized at an outstanding level. However, after stabilizing these patients (24-48 h later) treatment is easily scattered and coordination and follow-up may become difficult or even fully lost. As a result, longitudinal involvement of the trauma surgeon is challenging to achieve. Thus, in this perspective, it is reasonable to assume that, at least in our country, there might be an optimum of multitrauma patients per level 1 centre to strive for (Fig. 1) [35, 36]. For this, a larger catchment area per level 1 centre is probably necessary, and more frequent transport by air required. Whether these kind of numbers for further centralisation are achievable in the European and more specifically Dutch setting depends on the political ambitions and (supra-)regional agreements of all parties involved.

\section{Keeping the trauma surgeon alive?}

It can be concluded that further centralization to a limited number of level 1 trauma centres is essential to consolidate experience and knowledge for the trauma surgeon. However, the pitfall of centralisation is an overshoot in sub-specializations, as level 1 centres are often aligned with top referent and academic centres with inherent sub-specialisation for elective cases. Although it would be possible to go down this road of sub-specialisation in trauma with a sufficient number of patients, we feel that it is undesirable. The added value of

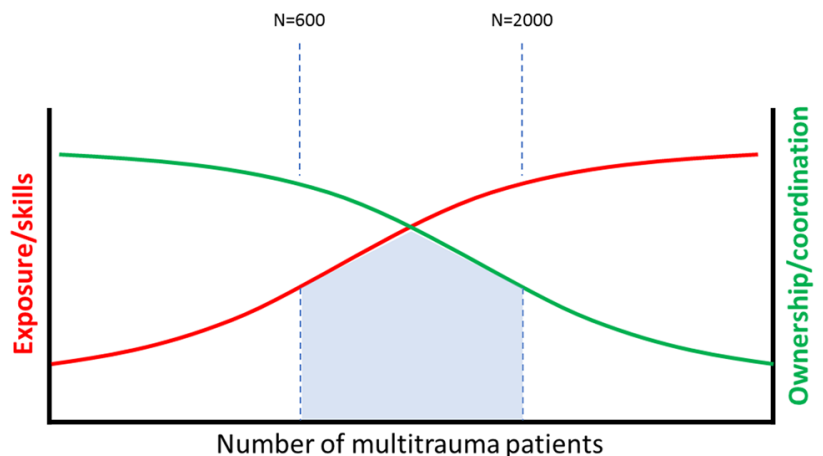

Fig. 1 The effect of patient numbers. In case of too low numbers of severely injured patients, insufficient expertise per centre will be available to reduce mortality rates and optimize the logistic process. However, when the number of patients is too high patient ownership and coordination is hampered. It is likely that an optimum for the number of patients per centre exists 
Table 3 Expertise and involvement with trauma per specialty

\begin{tabular}{llllll}
\hline & $\begin{array}{l}\text { Acute care } \\
\text { dedication }\end{array}$ & $\begin{array}{l}\text { Surgical } \\
\text { specialty }\end{array}$ & $\begin{array}{l}\text { Physiologic knowl- } \\
\text { edge (trauma specific) }\end{array}$ & $\begin{array}{l}\text { Long term care } \\
\text { Multi- } \\
\text { system } \\
\text { approach }\end{array}$ \\
\hline Emergency physicians & ++ & - & + & - & ++ \\
Anaesthesiologists & $+/-$ & - & ++ & - & \pm \\
Intensivists & + - & - & + & - & + \\
Orthopaedic surgeons & - & ++ & - & ++ & - \\
Abdominal surgeons & - & ++ & $+/-$ & ++ & - \\
Thoracic surgeons & - & ++ & - & - & - \\
Trauma surgeons & ++ & ++ & + & ++ & ++ \\
\hline
\end{tabular}

the trauma surgeon is longitudinal involvement in the care of injured patients and the broad, holistic scope of knowledge. Especially in the case of multiple injuries, the whole (the patient) is greater than the sum of its parts (separate injuries) [37]. Continuity of care and an integral treatment approach are essential for an optimal outcome [7].

The outcome in terms of mortality and functional recovery is mainly determined by timely diagnosis of injuries, the correct indication and timing of subsequent surgical procedures and the organisation of rehabilitation, in a continuous and aligned patient journey. As a consequence, someone has to be in charge of the process. This physician should be able to make a delicate decision between the different treatment strategies, both surgical and non-surgical, with knowledge of physiology, injuries and implications of treatment options and subsequent choices (Table 3). Physicians who are not actively involved in the surgical process will have a hard time balancing the decision, with a chance of less optimal outcome.

The challenge for the upcoming years will be to maintain the combination of competences, which can be depicted in model nowadays termed 'neo-generalist'. This 'tree-shape' comprises of a broad foundation of knowledge and skills in multiple aspects of general surgery and basic physiology. In addition, the branching lines in the model indicates the competences for specialisation, in this case trauma. As stated, due to the low mortality rates in recent years, focus shifts from surviving to functional recovery. The biggest threat of this shift to improved functional outcome, as mentioned earlier, is a far-reaching sub-specialisation and the loss of the trauma surgeon as a broad developed specialist. It was previously demonstrated that there is a clear correlation between specialised trauma surgery training and the level of trauma system development [38]. It is likely that far-reaching subspecialisation will come at the cost of success in reducing mortality. In the Netherlands, similar problems are encountered and described by Cardiologists and Psychiatrists in recent years [39-43].

The problem is that far-reaching sub-specialisation will lead to the disintegration of interrelated care and loss of focus of the patient as a whole. A balance should be sought between the width and depth of the expertise and skillset of the trauma surgeon. For this, it is supportive if trauma is seen as a disease entity and not as part of general duties when one is on call. In countries where the orthopaedic surgeon is in charge of trauma care, it can be challenging to provide integral lifesaving (damage control) surgery, especially when it concerns visceral injuries. On the other hand, in countries where the visceral surgeon is in charge of trauma care, a major part of injuries (and patients) is treated outside their scope as these concern only extremity injuries. This could result in a relative large number of missed or delayed diagnosed injuries [44, 45]. Additionally, when care is provided by a multitude of subspecialists, costs will rise extensively without a proven benefit for patients outcomes as stated previously [6]. It might be, that different countries choose different solutions for this rising problem. Nevertheless, in the inclusive trauma system, we have the opportunity to tune the competences of the surgeons to the needs of their patients in the different participating centres. Regardless of the centre and its position in the system, the injured patient needs a guide for longitudinal care, from presentation to rehabilitation.

In conclusion, there is good quality of care for the injured patient in the Netherlands, at the same time still room for improvement in the current cost-effective system. The goal for the upcoming years is to further centralise and differentiate in terms of function (expertise and organization) for the different levels of trauma centres. With this an even further reduction in mortality might be possible, while simultaneously aiming to improve functional outcome. The trauma surgeon as a specialist for injured patients is key in this model, being able to provide the vast majority of care, while for the remaining part, intramural, regional and national collaboration is essential.

\section{Compliance with ethical standards}

Conflict of interest Falco Hietbrink declares that he has no conflict of interest. R. Marijn Houwert declares that he has no conflict of interest. 
Karlijn J. P. van Wessem declares that she has no conflict of interest. Rogier K. J. Simmermacher declares that he has no conflict of interest. Geertje A. M. Govaert declares that she has no conflict of interest. Mirjam B. de Jong declares that she has no conflict of interest. Ivar G. J. de Bruin declares that he has no conflict of interest. Johan de Graaf declares that he has no conflict of interest. Loek P. H. Leenen declares that he has no conflict of interest.

Open Access This article is distributed under the terms of the Creative Commons Attribution 4.0 International License (http://creativeco mmons.org/licenses/by/4.0/), which permits unrestricted use, distribution, and reproduction in any medium, provided you give appropriate credit to the original author(s) and the source, provide a link to the Creative Commons license, and indicate if changes were made.

\section{References}

1. Ciesla DJ, Moore EE, Cothren CC, Johnson JL, Burch JM. Has the trauma surgeon become house staff for the surgical subspecialist? Am J Surg. 2006;192:732-7.

2. Goslings JC, Ponsen KJ, Luitse JS, Jurkovich GJ. Trauma surgery in the era of nonoperative management: the Dutch model. J Trauma. 2006;61:111-4 (discussion 5).

3. Hietbrink F, Smeeing D, Karhof S, Jonkers HF, Houwert M, van Wessem K, et al. Outcome of trauma-related emergency laparotomies, in an era of far-reaching specialization. World J Emerg Surg. 2019;14:40.

4. Timmers TK, Verhofstad MH, Leenen LP. Intensive care organisation: Should there be a separate intensive care unit for critically injured patients? World J Crit Care Med. 2015;4:240-3.

5. Hesselink L, Spijkerman R, van Wessem KJP, Koenderman L, Leenen LPH, Huber-Lang M, et al. Neutrophil heterogeneity and its role in infectious complications after severe trauma. World J Emerg Surg. 2019;14:24 (In press).

6. Allgower M. General surgery and trauma. Ann R Coll Surg Engl. 1975;57:133-8.

7. Sturm JA, Pape HC, Dienstknecht T. Trauma care in Germany: an inclusive system. Clin Orthop Relat Res. 2013;471:2912-23.

8. Moore EE, Maier RV, Hoyt DB, Jurkovich GJ, Trunkey DD. Acute care surgery: Eraritjaritjaka. J Am Coll Surg. 2006;202:698-701.

9. Lansink KW, Leenen LP. History, development and future of trauma care for multiple injured patients in the Netherlands. Eur J Trauma Emerg Surg. 2013;39:3-7.

10. de Knegt C, Meylaerts SA, Leenen LP. Applicability of the trimodal distribution of trauma deaths in a Level I trauma centre in the Netherlands with a population of mainly blunt trauma. Injury. 2008;39:993-1000.

11. Twijnstra MJ, Moons KG, Simmermacher RK, Leenen LP. Regional trauma system reduces mortality and changes admission rates: a before and after study. Ann Surg. 2010;251:339-43.

12. Spijkers AT, Meylaerts SA, Leenen LP. Mortality decreases by implementing a level I trauma center in a Dutch hospital. J Trauma. 2010;69:1138-42.

13. Lansink KW, Gunning AC, Leenen LP. Cause of death and time of death distribution of trauma patients in a level I trauma centre in the Netherlands. Eur J Trauma Emerg Surg. 2013;39:375-83.

14. Lansink KW, Gunning AC, Spijkers AT, Leenen LP. Evaluation of trauma care in a mature level I trauma center in the Netherlands: outcomes in a Dutch mature level I trauma center. World J Surg. 2013;37:2353-9.
15. Gunning AC, Lansink KW, van Wessem KJ, Balogh ZJ, Rivara FP, Maier RV, et al. Demographic Patterns and outcomes of patients in level i trauma centers in three international trauma systems. World J Surg. 2015;39:2677-84.

16. Jochems D, Leenen LPH, Hietbrink F, Houwert RM, van Wessem KJP. Increased reduction in exsanguination rates leaves brain injury as the only major cause of death in blunt trauma. Injury. 2018;49:1661-7.

17. Jochems D, van Wessem KJP, Houwert RM, Brouwers HB, Dankbaar JW, van Es MA, et al. Outcome in patients with isolated moderate to severe traumatic brain injury. Crit Care Res Pract. 2018;2018:3769418.

18. van der Vliet QMJ, Bhashyam AR, Hietbrink F, Houwert RM, Oner FC, Leenen LPH. Routine incorporation of longer-term patient-reported outcomes into a Dutch trauma registry. Qual Life Res. 2019;28:2731-9.

19. van der Vliet QMJ, van Maarseveen OEC, Smeeing DPJ, Houwert RM, van Wessem KJP, Simmermacher RKJ, et al. Severely injured patients benefit from in-house attending trauma surgeons. Injury. 2019;50:20-6.

20. van Wessem KJP, Leenen LPH. Incidence of acute respiratory distress syndrome and associated mortality in a polytrauma population. Trauma Surg Acute Care Open. 2018;3:e000232.

21. van Wessem KJP, Leenen LPH. Reduction in mortality rates of postinjury multiple organ dysfunction syndrome: a shifting paradigm? A prospective population-based cohort study. Shock. 2018;49:33-8.

22. van Laarhoven JJ, van Lammeren GW, Houwert RM, van Laarhoven CJ, Hietbrink F, Leenen LP, et al. Isolated hip fracture care in an inclusive trauma system: a trauma system wide evaluation. Injury. 2015;46:1042-6.

23. Wurdemann FS, Smeeing DPJ, Ferree S, Nawijn F, Verleisdonk E, Leenen LPH, et al. Differentiation in an inclusive trauma system: allocation of lower extremity fractures. World J Emerg Surg. 2018;13:18.

24. Moore L, Champion H, Tardif PA, Kuimi BL, O'Reilly G, Leppaniemi A, et al. Impact of trauma system structure on injury outcomes: a systematic review and meta-analysis. World J Surg. 2018;42:1327-39.

25. Moore L, Evans D, Hameed SM, Yanchar NL, Stelfox HT, Simons $\mathrm{R}$, et al. Mortality in Canadian trauma systems: a multicenter cohort study. Ann Surg. 2017;265:212-7.

26. Waibel BH, Rotondo MM. Damage control surgery: it's evolution over the last 20 years. Rev Col Bras Cir. 2012;39:314-21.

27. Poortman P, Meeuwis JD, Leenen LP. Multitrauma patients: principles of 'damage control surgery'. Ned Tijdschr Geneeskd. 2000;144:1337-411.

28. Hietbrink F, Simmermacher RKJ, de Vries MB, van Wessem KJP, de Jong MB, Leenen LPH. Emergency laparotomy in a trauma patient. Ned Tijdschr Geneeskd. 2017;161:D863.

29. Beks RB, de Jong MB, Houwert RM, Sweet AAR, De Bruin I, Govaert GAM, et al. Long-term follow-up after rib fixation for flail chest and multiple rib fractures. Eur J Trauma Emerg Surg. 2018:45:645-54.

30. Ferree S, van der Vliet QMJ, van Heijl M, Houwert RM, Leenen LPH, Hietbrink F. Fractures and dislocations of the hand in polytrauma patients: incidence, injury pattern and functional outcome. Injury. 2017;48:930-5.

31. van der Vliet QMJ, Sweet AAR, Bhashyam AR, Ferree S, van Heijl M, Houwert RM, et al. Polytrauma and high-energy injury mechanisms are associated with worse patient-reported outcomes after distal radius fractures. Clin Orthop Relat Res. 2019;477:2267-75.

32. Zorg LNA. Landelijke trauma registratie; 2018. https://www.lnaz. nl/cms/18.335_LNAZ_LTR_Rapportage-2013-2017.pdf. 
33. Traumachirurgie NVv. Level criteria; 2019. https://www.traum a.nl/levelcriteria-nvt.

34. Cole E, Lecky F, West A, Smith N, Brohi K, Davenport R. The impact of a pan-regional inclusive trauma system on quality of care. Ann Surg. 2016;264:188-94.

35. Alali AS, Gomez D, McCredie V, Mainprize TG, Nathens AB. Understanding hospital volume-outcome relationship in severe traumatic brain injury. Neurosurgery. 2017;80:534-42.

36. Nathens AB, Jurkovich GJ, Maier RV, Grossman DC, MacKenzie EJ, Moore M, et al. Relationship between trauma center volume and outcomes. JAMA. 2001;285:1164-71.

37. Levi $\mathrm{M}$. The general physician in the modern specialized medicine. Dying breed or indispensable? Ned Tijdschr Geneeskd. 2009;153:112-3.

38. Leppaniemi A. A survey on trauma systems and education in Europe. Eur J Trauma Emerg Surg. 2008;34:577-81.

39. van der Meer J, Kievits F. Ziekten bestaan niet, zieken wel. Ned Tijdschr Geneeskd. 2000;144:2164-5.
40. Redelmeier DA, Tan SH, Booth GL. The treatment of unrelated disorders in patients with chronic medical diseases. N Engl J Med. 1998;338:1516-20.

41. van Twillert M. Superspecialisatie heeft ook keerzijde. Medisch Contact. 2017;46:14-5.

42. Beeres M. Superspecialisatie maakt GGZ vleugellam. Medisch Contact. 2017;29:22-4.

43. Broersen S. Superspecialisatie vraagt om regie van algemeen cardioloog. Medisch Contact. 2018; 8-10.

44. van der Vliet QMJ, Lucas RC, Velmahos G, Houwert RM, Leenen LPH, Hietbrink F, et al. Foot fractures in polytrauma patients: Injury characteristics and timing of diagnosis. Injury. 2018;49:1233-7.

45. Ferree S, Houwert RM, van Laarhoven JJ, Smeeing DP, Leenen LP, Hietbrink F. Tertiary survey in polytrauma patients should be an ongoing process. Injury. 2016;47:792-6. 